\title{
Cross-modality set effect on the perception of ambiguous pictures
}

\author{
AN-YEN LIU \\ Jackson State University, Jackson, Mississippi 39217
}

\begin{abstract}
Before viewing an ambiguous picture which could be perceived into alternatives, an auditory stimulus was presented to undergraduates to effect perceptual set. It was found that both relevant verbal description and music recording were effective in affecting subjects' responses. A short taped message, discussing the body dimensions and life conditions of various rats, generated significantly more rat responses in the experimental group where the rat/man drawing was shown. A horror music recording was also found effective in significantly increasing the old woman response of Leeper's wife/mother-in-law ambiguous drawing. There seems to exist a relationship between the nature of a drawing and the effectiveness of a set. In order to effectively influence the perception of a drawing like the $\mathrm{rat} / \mathrm{man}$ picture, a nondetailed yet related message is needed. The function of the auditory sets was interpreted to be the establishment of ill-defined categories which are powerful aids to perception-recognition.
\end{abstract}

Both visual (related pictures) and auditory stimuli (verbal descriptions) have been used to investigate the effect of set on the perception of ambiguous pictures. Leeper's (1935) early study of the well known wife/ mother-in-law drawing found that verbal description of the figure emphasizing the old woman alone or the young lady alone failed to affect perception of the test figure. However, a related, biased version of the picture was effective. Repetitions of this experiment by Epstein and Rock (1960) yielded similar results.

Bugelski and Alampay (1961), using the rat/man drawing, found that the frequency with which the rat was observed increased as a function of the number of animal pictures seen previously. No frequency effect for human pictures was found. These findings seem to indicate that visually induced perceptual set is generally effective in affecting subjects' perception of the ambiguous picture.

On the other hand, contradicting results were found when an auditory stimulus was introduced to provide a set for the perception of an ambiguous drawing. Three groups of subjects were asked to perceive Street's oceanliner drawing by Steinfeld (1967). Subjects who listened to a ship story were found to perceive and to organize the picture as a ship much more quickly than subjects who were told either an irrelevant story or no story.

In explaining the discrepancy between his finding and those of the earlier studies, Steinfeld (1967) argued that the structural difference between drawings might have caused the variation. Both the wife/mother-in-law and

The author wishes to thank Jeff S. Topping, who sponsors this paper and takes full editorial responsibility for it. Thanks are also due Patrick Griffin for his assistance and Cynthia Ford for her help with the data collection in Experiment II. the rat/man drawings contain clear binary alternatives. However, in the ocean-liner picture the alternatives are not obvious. Such a fragmented drawing has to be organized before a meaningful percept can result. A verbal description of the picture or a related story about the picture can thus be helpful in organizing a meaningful percept. The shorter response time in subjects provided with a relevant set supports this notion.

These findings seem to suggest a relation between the effectiveness of a perceptual set and the structure of the focal visual stimulus. In the case where a drawing can be perceived into alternatives easily, a detailed description of the drawing may create negative effect. That is, an explicit, detailed description of the picture may direct the subject to focus on the fine components of the drawing, thus prolonging the reaction time.

The relationship between ill-defined categories and sets is stressed by Neisser (1967). According to Neisser, when a subject is "set" to expect something, what he has in readiness is an ill-defined category. Such a category is a powerful aid to pattern recognition because assignment to a category usually leads to identifications. Based on these observations, it is reasoned that in order to effectively influence an individual's perception of an ambiguous picture, such as the rat/man drawing, a related but nondetailed verbal description is needed. The function of such a description is to establish an ill-defined category before visualizing the drawing. It is expected that a global ill-defined category, which will not divert a perceiver's attention to fine details, will facilitate identification.

This paper reports two experiments which demonstrated that relevant auditory stimuli, capable of establishing ill-defined categories, can be introduced to affect the perception of an ambiguous picture such as 
Table 1

Responses to the Ambiguous Rat/Man Figure

\begin{tabular}{lccrrrrrr} 
& \multicolumn{9}{c}{ Response } \\
Group & \multicolumn{1}{c}{ Rat } & \multicolumn{2}{c}{ Man } & \multicolumn{2}{c}{ Both } & \multicolumn{2}{c}{ Neither } \\
\hline Control & 14 & $(38)$ & 17 & $(46)$ & 4 & $(11)$ & 2 & $(5)$ \\
Group 1 & 10 & $(35)$ & 14 & $(48)$ & 4 & $(14)$ & 1 & $(3)$ \\
Group 2 & 19 & $(70)$ & 5 & $(19)$ & 2 & $(7)$ & 1 & $(4)$ \\
\hline
\end{tabular}

Note-Number in parentheses is the percentage of the response.

Leeper's wife/mother-in-law drawing, where binary alternatives can be perceived easily.

\section{EXPERIMENT I}

\section{Method}

Subjects. Ninety-three undergraduates, enrolled in general psychology, participated in this study for extra course credit. Thirty-seven were assigned to the control group, 29 to Experimental Group 1, and 27 to Experimental Group 2. Sex was not balanced across different groups.

Stimuli. The rat/man picture used by Bugelski and Alampay (1961) was projected on a screen to provide the visual stimulus. Two taped messages were used as auditory stimuli. For Experimental Group 1, the message was adopted from Form A, Judgment and Comprehension of Flanagan Aptitude Classification Tests (Flanagan, 1953). This taped message discussed job promotion, pay schedule, and quality for job success. The message presented to Experimental Group 2 was adopted from The World Book Encyclopedia (1975). This message discussed different types of rats in terms of their body dimensions and life conditions. The length of the message for Group 1 was $186 \mathrm{sec}$ and $210 \mathrm{sec}$ for Group 2.

Apparatus and Procedure. Subjects were informed about the experimental procedures without mentioning the nature of the picture and the content of the questionnaire before listening to the taped message. They were asked to remain silent throughout the experimental session.

In a regular classroom setting, with all lights off, subjects in Experimental Group 1 first listened to the taped message. As soon as the message was over, the ambiguous drawing was projected on a screen for $30 \mathrm{sec}$. Immediately afterward, the subjects completed a short questionnaire with the following questions: (1) Did you see any particular object in the picture? What did you see? Please describe the picture. (2) Did you see the picture (or a similar one) before? If you did, where did you see it? (3) According to your opinion, what does the taped message deal with? There was no time restraint for the subject to respond.

For Question 1 answers such as rat, mouse, rodent, and the like were scored as a rat response; answers such as man, old man, white man, bald head, etc., were classified as a man response. If both man and rat were mentioned, it was scored as both. Other responses were classified as neither. Statistical analysis was based on subjects' responses to Question 1. The purpose of Question 2 was to eliminate those who had previous experience with the drawing. Question 3 was used to evaluate subjects' understanding of the taped message. It was found that subjects comprehended the message without difficulty.

For Experimental Group 2, the same procedure and condition applied with the exception of a different taped message. The control group received no auditory stimulus before viewing the ambiguous drawing for the same amount of time as the experimental groups.

\section{Results and Discussion}

Subjects' responses to the ambiguous picture are presented in Table 1. For the control group, where no auditory stimulus was presented, $46 \%$ of the subjects saw man and $38 \%$ saw rat. The rest of this group either saw both alternatives of the picture or saw something other than a rat or man. Bugelski and Alampay (1961) reported that $81 \%$ of their control group saw a man. It is not clear to what extent this difference can be accounted for by the ethnic background of the two samples. Procedual differences may also have caused the discrepancy.

The taped message concerning the employment practices was ineffective in affecting the perception of the subjects. However, the subjects who listened to the rat descriptions before viewing the ambiguous picture described the drawing as a rat more frequently than did the control group. The difference was found to be significant, $\chi^{2}(1)=11.32, p<.01$. This finding lends support to the claim that a related yet nonspecific verbal set can affect the perception of a readily organizable drawing like the rat/man picture.

As indicated earlier, Leeper (1935) reported that an explicit, detailed description of one of the alternatives of the wife/mother-in-law figure was not effective in determining which alternative was seen. One plausible explanation is that the detailed description of an alternative might have set the subject to focus on and search for the fine components of the described drawing. Such a specific and detailed description could have caused the subject difficulty in perceiving the picture as a whole, which was the desired response. Neisser (1967) argued that an ill-defined category enables an individual to perceive an ambiguous drawing in a certain way. The function of a set seems to be the establishment of an ill-defined category. This implies that a set will be effective as long as an ill-defined category can be created through that set. Experiment II demonstrated that some form of auditory stimulus other than verbal description, which is capable of creating an ill-defined category, can be introduced to affect the perception of an ambiguous drawing with compelling alternatives.

\section{EXPERIMENT II}

\section{Method}

Subjects. Fifty-three undergraduates enrolled in general psychology classes participated in the study for extra course credit. Eighteen subjects were assigned to the control group, 21 to the horror music group, and 14 to the soft music group. Sex was not balanced across different groups.

Apparatus and Procedure. In a classroom setting with all lights off, subjects in the experimental groups were asked to concentrate and use their imagination to project themselves into the music which was presented to them through a record player. The soft music used was entitled "You're as Right as Rain" by the Stylistics. "Chilling, Thrilling Sounds of the Haunted House" by the Sounds Effects Department of Walt Disney Studio was played for the horror music group. Immediately after listening to the music, subjects were asked to view the wife/mother-in-law picture, which was projected on the screen for $1 \mathrm{~min}$. Then they were asked to describe the picture in detail by completing a short questionnaire like the one described in Experiment I. The control group viewed the ambiguous drawing without receiving 
Table 2

Responses to the Ambiguous Wife/Mother-in-Law Figure

\begin{tabular}{lccccc}
\multicolumn{1}{c}{ Group } & \multicolumn{4}{c}{ Response } & \\
Wife & \multicolumn{4}{c}{ Mother-in-Law } & $\mathrm{n}$ \\
\hline Control & 16 & $(89)$ & 2 & $(11)$ & 18 \\
Horror Music & 12 & $(57)$ & 9 & $(43)$ & 21 \\
Soft Music & 12 & $(86)$ & 2 & $(14)$ & 14 \\
\hline
\end{tabular}

Note-Number in parentheses indicates the response percentage.

any auditory stimulus. Those responses related to young lady, pretty girl, a girl, and the like were scored as wife. Responses related to witch, old lady, ugly woman, etc., were scored as mother-in-law.

\section{Results and Discussion}

Table 2 presents the responses to the wife/mother-inlaw picture under the different conditions. Where subjects listened to the horror music before viewing the picture, $43 \%$ reported seeing the old woman or witch. In the soft music condition, only $14 \%$ of the subjects saw the old woman alternative. This alternative was seen by $11 \%$ of the subiects in the control group. The difference in responding between the control group and the group receiving horror music was significant, $\chi^{2}(1)=21.75$, $\mathrm{p}<.01$. There was no significant response difference between the control group and the soft music group.

Music has long been known to be effective in creating certain moods in its audience. An individual's mood can affect his/her perception at the moment. Since the subjects were asked to concentrate and to use their imagination to project themselves into the music, subjects listening to the horror music seemed to have created a scary scene within themselves. A scary scene, which is an illdefined category, engendered the perception of a witch or an old lady.
These experiments demonstrated that both relevant verbal description and music recording can produce perceptual set effects. Nevertheless, we do not fully understand the mechanism of the different sets which were introduced by the different stimuli. It is evident that a set introduced by a music recording is quite different from one introduced by a verbal description. However, it was indicated that there exists a close relationship between sets and ill-defined categories. Thus, it seems equally plausible that both verbal description and music recording established ill-defined categories within the subjects. The establishment of such an ill-defined category facilitates the perception of a certain alternative of the visual stimulus.

\section{REFERENCES}

Bugelski, B. R., \& Alampay, D. A. The role of frequency in developing perceptual sets. Canadian Journal of Psychology, 1961, 15, 205-211.

Epstein, E., \& Rock, I. Perceptual set as an artifact of recency. American Journal of Psychology, 1960, 73, 214-228.

Flanagan, J. C. Flanagan aptitude classification tests. Chicago: Science Research Associates, 1953.

LEEPER, R. A study of a neglected portion of the field of learningThe development of sensory organization. Journal of Genetic Psychology, 1935, 46, 41-75.

NeIsser, U. Cognitive Psychology. New York: Appleton-CenturyCrofts, 1967. Pp. 58-61.

StEINFELD, G. J. Concepts of set and availability and their relation to the reorganization of ambiguous pictorial stimuli. Psychological Review, 1967, 74, 505-522.

Street, R. F. A Gestalt Completion Test: A study of a crosssection of intellect. New York: Bureau of Publication, Teachers College, Columbia University, 1931.

The World Book Encyclopedia (Vol. 16). New York: Field Enterprise Educational Corporation, 1975. Pp. 141-142.

(Received for publication November 13, 1975.) 